\title{
Critically problematising existing organisational identity theory against practice: Part 1 - The thinking framework of organisational identity
}

\begin{tabular}{|c|c|}
\hline \multicolumn{2}{|c|}{$\begin{array}{l}\text { Authors: } \\
\text { Theo H. Veldsman }{ }^{1} \text { (1) } \\
\text { Dieter Veldsman }{ }^{1}\end{array}$} \\
\hline \multicolumn{2}{|c|}{$\begin{array}{l}\text { Affiliations: } \\
{ }^{1} \text { Department of Industrial } \\
\text { Psychology and People } \\
\text { Management, College of } \\
\text { Management and Economics, } \\
\text { University of Johannesburg, } \\
\text { Johannesburg, South Africa }\end{array}$} \\
\hline \multicolumn{2}{|c|}{$\begin{array}{l}\text { Corresponding author: } \\
\text { Theo Veldsman, } \\
\text { theoveld@mweb.co.za }\end{array}$} \\
\hline \multicolumn{2}{|c|}{$\begin{array}{l}\text { Dates: } \\
\text { Received: } 17 \text { Mar. } 2020 \\
\text { Accepted: } 07 \text { May } 2020 \\
\text { Published: } 22 \text { July } 2020\end{array}$} \\
\hline \multicolumn{2}{|c|}{$\begin{array}{l}\text { How to cite this article: } \\
\text { Veldsman, T.H. \& Veldsman, D. } \\
\text { (2020). Critically problematising } \\
\text { existing organisational } \\
\text { identity theory against } \\
\text { practice: Part } 1 \text { - The } \\
\text { thinking framework of } \\
\text { organisational identity. } \\
\text { SA Journal of Industrial } \\
\text { Psychology/SA Tydskrif vir } \\
\text { Bedryfsielkunde 46(0), a1799. } \\
\text { https://doi.org/10.4102/ } \\
\text { sajip.v46i0.1799 }\end{array}$} \\
\hline \multicolumn{2}{|c|}{$\begin{array}{l}\text { Copyright: } \\
\text { (C) 2020. The Authors. } \\
\text { Licensee: AOSIS. This w } \\
\text { is licensed under the } \\
\text { Creative Commons } \\
\text { Attribution License. }\end{array}$} \\
\hline \multicolumn{2}{|l|}{ Read online: } \\
\hline 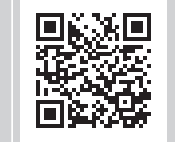 & $\begin{array}{l}\text { Scan this QR } \\
\text { code with your } \\
\text { smart phone or } \\
\text { mobile device } \\
\text { to read online. }\end{array}$ \\
\hline
\end{tabular}

Orientation: Organisations are embedded in an emerging, radically and fundamentally changing world of work is forcing them to consider deeper issues such as who are we? and why do we exist?

Research purpose: To problematise critically the current organisational identity (OI) literature's power to provide deep insight into practice based findings resulting from an OI intervention in a major global, South African organisation. Part 1 covers the research purpose and approach; describes the large-scale OI intervention reported on; and problematises critically the thinking framework of OI: its meta-theoretical lenses, vocabulary and meta-theoretical framework.

Motivation for the study: In this world, OI has become critically important as a secure and referent anchor.

Research approach/design and method: Conventional or non-conventional grounded theory was utilised. We moved the data generated from the lived, enacted experiences of participants to existing theory and then used the generated findings to question OI theory by validating in an exploratory manner it to expose the current literature's strengths, weaknesses and blind spots from a practice or practitioner's power of understanding vantage point.

Main Findings: From a practice perspective, the OI literature was highly relevant, robust and valid in making sense of and giving meaning to what was observed during the OI intervention. However, practice-wise, a number of significant weaknesses also were uncovered.

Practical/managerial implications: The current IO literature proved with some limitations to be of practice utility.

Contribution or value-add: Theoretical and practical recommendations were made to strengthen the existing OI literature from a practice perspective.

Keywords: grounded theory; organisational identity; individual identity; practice-problematised theory; qualitative research.

\section{Introduction}

Organisations are embedded in a radically, fundamentally changing Viccas (an extension of Vuca) world of work of increasing Variety, Interdependency, Complexity, Change, Ambiguity and Seamlessness (Veldsman, 2016b). Organisational members are forced to think more broadly than the question what do we do? by considering deeper issues such as who are we? and why do we exist? as part of interrogating the continued relevance of the organisation's purpose (Murray, 2019; The British Academy, 2019). Under these conditions, the concepts of organisational and individual identities have become critically important (Pioch \& Gerhard, 2014) in providing secure and referent anchors in the emerging Viccas world of hyper-fluidity and hyper-turbulence (Sillince \& Golant, 2018).

Numerous studies position organisational identity (OI) as a key competitive differentiator through providing a competitive edge, retaining talent, driving performance and creating an engaged, purpose-driven workforce (Pioch \& Gerhard, 2014; Rockwell, 2019). It is contented that OI is of central importance as root metaphor in organisational studies (Alvesson, Ashcraft, \& Thomas, 2008; Brown, 2015; Gioia, Patvardhan, Hamilton, \& Corley, 2013; Pratt, Schultz, Ashforth, \& Ravashi, 2016). However, in some quarters, the value and utility of the concept of OI in practice, specifically in the emerging, new world of work, is being questioned (Martínez, Pérez, \& Del Bosque, 2014). 


\section{Research purpose and targeted literature}

The concept of identity is central to the very existence of people, organisations, communities and society (Ashforth, 2016a; Brown, 2015; Caza, Vough, \& Puranik, 2018; Gioia et al., 2013; Pratt et al., 2016). Organisational identity is an integrative root concept at the foundation of, and a fulcrum point for, the field of organisational science (Ashforth, Harrison, \& Corley, 2008; Gioia, Schultz, \& Corley, 2000; Gioia et al., 2013; Haslam, Cornelissen, \& Werner, 2017; Pratt et al., 2016). It is a highly researched topic: 16800 Google Scholar hits were logged between 1985 (the year of Albert and Whetten's seminal paper on OI) and 2015 (Pratt et al., 2016). In an updated search which we undertook in 2019, the number of hits had increased to over 4 million using the search term 'Organisational Identity'.

The purpose of our research was to perform a critical review of the existing literature on OI (and, to a lesser extent, individual identity) in terms of its current power to provide deep insights regarding $\mathrm{OI}$ in practice. To this end, we used the findings derived from a longitudinal organisational intervention by a major global South African organisation, which endeavoured to change its OI over 8 months as part of an overall turnaround strategy.

In doing so, we also sought to extend the dominant context of current OI research beyond the limits of North America and Europe (Caza et al., 2018) and into Africa - specifically South Africa - in an attempt to demonstrate the relevancy (or lack thereof) within a different context of the existing OI literature.

Our intention thus is to highlight both the strengths and gaps in the current OI literature from a practice perspective and to suggest how to enrich and extend the extant body of knowledge, both theoretically and practically. We therefore wish to problematise (Alvesson \& Sandburg, 2011) the extant literature from a practice point of view in terms of its practice power of understanding, with the aim of strengthening recursively speaking - both OI theory and practice.

\section{Respective purposes of parts 1 and 2 of our article}

Part 1 describes the large-scale OI intervention reported on. It next proceeds successively to critically problematise current OI meta-theoretical lenses and OI vocabulary, as well as the meta-theoretical framework applied to the territory called 'Organisational Identity'. In essence, Part 1 of our article deals with the Thinking Framework of the existing OI literature.

Part 2 - in essence, OI in action: the 'application' side of the OI Thinking Framework - will cover critically problematisation the existing OI literature with respect to the here-and-now dynamics of OI, the evolution and change of OI over time and the outcomes of OI work. This article ends off with highlighting the implications for OI practice and theory arising from our practice-referenced, problematising review of the existing OI literature.

\section{Research approach Research design}

The overall research design we adopted to meet our research purpose was located in the space of grounded theory (Amsteus, 2014; Corley, 2015; Eisenhardt, Graebner, \& Sonenshein, 2016; Fendt \& Sachs, 2008; O’Reilly, Paper, \& Marx, 2012; Walsh et al., 2015). The design utilised conventional grounded theory, in that it was inductive, that is, moving from data generated from the lived, enacted experiences of participants - resulting from a large-scale OI intervention as a single, qualitative, longitudinal case study (see below) - to the existing theory.

Our design also encompassed non-conventional grounded theory. We did not primarily use the generated findings to build theory progressively, but rather to validate - in an exploratory manner - existing theory on OI (i.e. using extant literature). In doing so, we wished to explicate its strengths, weaknesses and blind spots from a practice or practitioner's power-of-understanding vantage point. Our intention was to open up new and deepened OI insights, both practically and theoretically regarding OI across contexts, using a qualitative research design, at present dominant in the OI field (Caza et al., 2018).

\section{Critical reflections on our adopted research approach}

The typical critiques against grounded theory as qualitative research approach are the replication and restricted generalisability of findings beyond the specific setting of the study. We believe our research overcomes these purported critiques through, firstly, the longitudinal nature of the findings reported here -33 dialogue sessions over 8 months (see below), and, secondly, through abductive reasoning in a generalising manner set out to problematise the existing OI literature using our findings.

\section{The large-scale organisational identity change intervention}

\section{The organisation}

A global, South African organisation within the hospitality and gaming industry (hereafter Organisation $\mathrm{ABC}$ ) undertook the OI intervention which we report on here. Established during the early 1980s, the organisation has since expanded its operations across Africa, Latin America and - through partnerships - into Asia. The intervention took place in the South African division of the organisation.

\section{The need for, and make-up of, the large-scale organisational identity intervention}

Given the changing nature of its industry, pressure from new competition and declining business performance, Organisation ABC embarked on a turnaround strategy to strategically redefine, align, and streamline its core operations. The change also entailed a redefinition of its 
core identity as a gaming business, with hospitality becoming a secondary leg of its operations. This shift implied significant changes in terms of brand positioning, resource allocation and the people competencies the organisation required to drive and support its new business direction and OI.

Figure 1 depicts the different components of the people effectiveness strategy of Organisation $A B C$, and how these informed the intervention. For the purposes of our article, only the last phase of the intervention - values definition - is relevant and discussed here.

The final phase of the intervention (depicted in Figure 1) entailed the definition of a revised values framework. That is, the OI intervention process in which the second author was directly involved as a consultant. This process proceeded as follows:

- Phase 1: Intense, semi-structured dialogue sessions during which employees interpreted the vision, mission and brand of Organisation ABC and provided input into crafting a behavioural library that they believed aligned with the recrafted OI, that is, If this is who we are $\rightarrow$ This is what we do $\rightarrow$ This is how we do it.

- Phase 2: Consolidation of themes, using a thematic network analysis approach that consolidated the behavioural library into categories of behaviour, which employees then tagged by assigning category names to

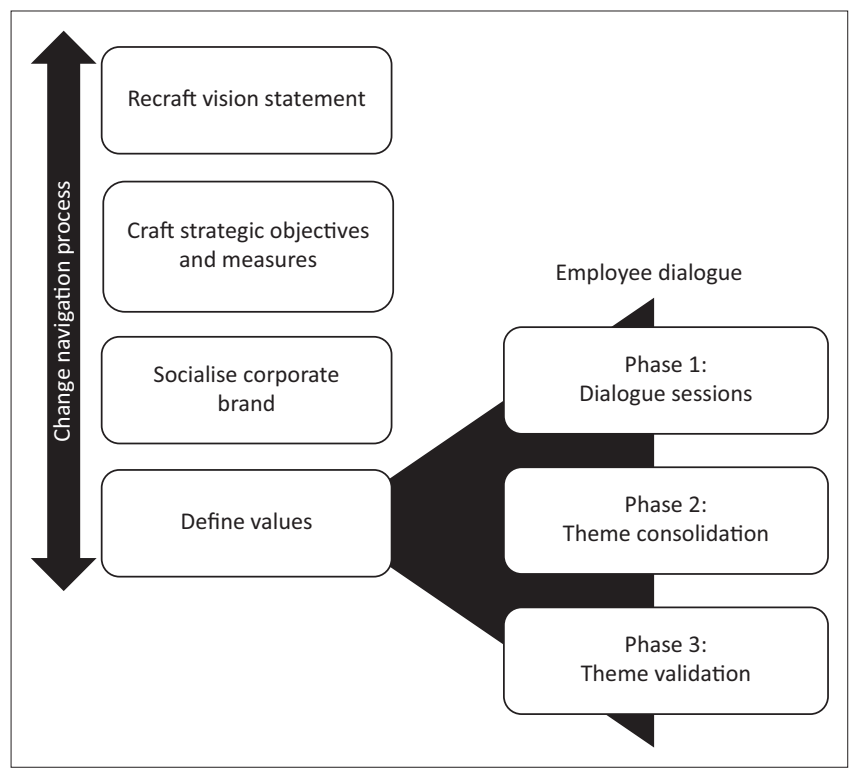

FIGURE 1: Broader people effectiveness strategy of Organisation $A B C$ and its relationship to the organisational identity intervention. each cluster of behaviours (see Sample, Data Collection and Analysis below).

- Phase 3: Validation of the category names, behaviours, and associated descriptors, with all employees. We used a forced ranking technique to rank categories in terms of importance and relevance.

\section{Sample, data collection and analysis}

Table 1 provides an overview of the sample, the data collection approach we followed and the methods we applied during the OI intervention.

We analysed the data using thematic network analysis (Nowell, Norris, White, \& Moules, 2017). Through the analysis, we arrived at a deeper understanding of the data, by organising it into lower-order premises evident in the text (i.e. basic themes), categorising the themes into more abstract principles and studying the themes in the context of the wholeness of the text (cf. Attride-Stirling, 2001).

To ensure the quality of the data, the second author employed external observers during the dialogue sessions to validate the accuracy of the information gathered and the inductions made from the observations made. To this end, he undertook a structured validation process with participants to ensure the 'believability' (or credibility) of the data. Next, a specified semi-structured process was followed for all data collection methods that the second author documented and reviewed accordingly. This approach adhered to the guidelines proposed by Eisenhardt et al. (2016) and Webster and Mertova (2007).

\section{Ethical consideration}

Apart from protecting individual confidentiality and the non-disclosure of any confidential company information, such as the OI arrived at, we did not have to address any significant ethical concerns during the study. Permission was obtained from the parties concerned to report publically on the findings of the study.

\section{Findings}

The findings made are based on the progressively validated, inductively derived, grounded theory, observations made (Eisenhardt et al., 2016; Pratt, 2016) of the unfolding process of identity work during 33 dialogue sessions involving 4612 employees in Organisation ABC over 8 months (which the second author facilitated throughout as consultant) and

TABLE 1: Data collection approach and methods applied during the organisational identity intervention.

Data collection method
Formal organisational documentation
Informal narrative discussions
Semi-structured dialogue workshops
Observations

Informal, semi-structured, narrative inquiry-based discussions $(n=18)$ with the senior leadership and project teams to understand their perspectives and experience of the organisation to date

Intense, semi-structured dialogue sessions $(n=33)$ across all the business units over 8 months, attended by 4612 employees Participative observation by the second author, who was part of the organisational setting applicable to the intervention research over a period of 24 months, of which 8 months were spent on the organisational identity intervention 
the unfolding organisational dynamics within and around the process. Our observed findings are reported progressively through the below, unfolding process of our critical problematising of the current OI literature from a practice perspective in our endeavour to make sense and give meaning to our observations, using extant $\mathrm{OI}$ literature.

\section{Critically problematising current meta-theoretical lenses to view organisational identity}

Researchers typically apply three meta-theoretical lenses that is, world views or ontologies - in viewing OI, which we list in approximate order of popularity, as reflected in the literature: the functionalist, interpretivist (or social constructionist) and critical (Ashforth \& Schinoff, 2016; Bhatt, Van Riel, \& Baumann, 2016; Mujib, 2017). These lenses differ from the meta-theoretical perspectives - to be discussed below - that are used to understand OI. Most authors exclusively use a single lens to investigate OI.

Briefly, each of the lenses for viewing identity - including OI - entails the following:

1. Functionalist - one-on-one, linear cause-and-effect relationships between antecedents (elements), moderators of identity and outcomes.

2. Interpretivist - identity as ongoing co-construction through social interactions in the form of dialogue (or narratives) amongst a set of persons embedded in, and stakeholders of, the organisation.

3. Critical (post-structuralist or postmodern) - identity as a result of who holds power (internally and external to the organisation) and how they use their power to make, impose, regulate and legitimise identity.

Missing from the OI literature is a complexity/chaos (Boulton, Allen, \& Bowman, 2015; Veldsman, 2016b), which allows one to view identity as an interconnected whole of reciprocally influencing, interacting variables, where everything affects everything else. The interconnected whole is characterised by the ongoing resolution of dynamic, opposing tensions manifesting in the continuous, non-linear emergence of unpredictable, self-organising and self-destructing patterns. Pattern dynamics are the manifestation of a limited number of underlying organising rules. As interconnected wholes, patterns move through successive states of chaos (i.e. the absence of a discernible pattern) and order (i.e. the presence of a clear pattern), to converge over time into either an upward/virtuous or downward/vicious cycle.

The first problematising meta-insight gained from the OI intervention reported on here was the imperative to apply multiple lenses to take adequate account of the richness and multi-dimensionality of OI, both in theory and in practice. During the intervention, we found in practice that the functionalist lens, with its uni-directional, linear, causal approach, proved severely wanting and restrictive in terms of understanding the reciprocally interacting, multi-dynamic, multi-dimensional and organic nature of OI elements as observed in our findings.

Using the additional three lenses contributed significantly to a richer understanding of the intervention findings. Firstly, we required a complexity/chaos lens for holistic insight into OI with its interdependent, reciprocally influencing constituent elements, both conceptually and practically. Secondly, we needed an interpretivist lens to understand OI as something which individuals and organisations dynamically and continuously co-construct. Thirdly, a critical lens provided insight into the impact of power in shaping the OI process and outcomes. Given this initial meta-insight arising out of the richness of our OI findings, we use all three lenses in the discussion which follows.

\section{Critically problematising the existing organisational identity vocabulary informing the organisational identity narrative}

\section{Identity}

Identity refers to the definition or claim of who and what I am/ what we are; what we stand for, do, belong to, and aspire to - in short: How do I see myself/we see ourselves? How am I seen/are we seen? (Ashforth, 2016a; Ashforth \& Schinoff, 2016; Caza et al., 2018; Humphreys \& Brown, 2002; Lee, Park, \& Koo, 2015; Pratt et al., 2016).

\section{Organisational identity}

Organisational identity (we, us and them) relates to organisational members' understanding of who and what their organisation is, what it stands for and does, whom it belongs to and what it aspires to: How do we see ourselves? How are we seen? For organisational members, OI manifests in different forms: as espoused, desired/ideal, projected, actual and construed. The meta-theoretical perspective applicable here is that of the organisation as a social actor (or agent) (Albert, Ashworth, \& Dutton, 2000; Ashforth \& Schinoff, 2016; Gibney, Zagenczyk, Fuller, Hester, \& Caner, 2011; Gioia et al., 2000; Kreiner \& Murphy, 2016; Lee et al., 2015; Miscenko \& Day, 2016; Pratt et al., 2016; Ravashi, 2016; Van Tonder, 2004).

In the intervention we validated the utility of the above definition and forms (or categories) of identity and OI as currently advanced in the literature. We found them invaluable in terms of enabling us to construct a wellgrounded, definitional categorisation of our findings.

The most commonly propagated distinguishing features of OI - since Albert and Whetten's 1985 seminal paper - are the organisation's core, distinctive and enduring attributes (Albert \& Whetten, 1985; Ashforth, 2016a; Humphreys \& Brown, 2002; Kiriakidou \& Millward, 2000; Pratt et al., 2016). 
These notions resonated well with our findings in respect of the distinguishing OI features of Organisation ABC, especially as regards the attributes of distinctive and enduring. This was especially visible in organisational members' emotional attachment to the historical OI of Organisation $A B C$, as propagated by its founders, which endured even though some of the actual meaning ascribed to attributes had shifted in the organisation over time.

\section{Organisational image (or reputation)}

Organisational image (or reputation) pertains to external stakeholders' public understanding, impressions, expectations and judgements of who and what an organisation is and what it stands for, what it does, who it belongs to and what it aspires to: This is how we see you. The meta-theoretical perspective applicable here is that of institutional forces impacting on the organisation (Caza et al., 2018; Gioia et al., 2000, 2013; Hatch \& Schultz, 2002; Van Tonder, 2004).

We obtained validation for this perspective on OI during the intervention, which external stakeholders triggered because of concerns about the organisation's extant external image. Throughout the intervention, we had to 'back translate' the desired organisational image into the newly crafted, aspirational OI.

\section{Corporate identity (or brand)}

Corporate identity (or brand) encompasses the visible, tangible representations of what the organisation is and what it stand for, as contained and expressed in its name, logo, symbols, dress code, products or services, communication material (internal and external), which it uses in an effort to differentiate itself from other organisations. In this instance, the meta-theoretical perspective relevant here entails marketing and advertising (Ashforth, Schinoff, \& Rogers, 2016; Askegaard, 2001; Kiriakidou \& Millward, 2000; Van Rekom, 1997; Van Riel \& Balmer, 1997; Van Tonder, 2004).

Although the focus of the intervention was not on corporate identity, this definitional category in the OI-related literature proved valuable in alerting us to the criticality of aligning organisational and corporate identities as a next important step in the intervention process.

\section{Individual identity}

Individual identity consists of personal and social identity: the former is the self-referential definition of oneself: How do I see myself? It assumes different forms (my current, desired, feared, projected, and experienced self). By contrast, the latter is how one defines oneself in terms of the very same attributes which collectively define the social entity one belongs to: This is where I belong/want to be, because we are the same. A person has as many social identities as $\mathrm{s} /$ he has group memberships. Often, tensions exist between an individual's personal (me) identity and these multiple social identities (we), as well as between the latter identities themselves, all of which constitute the challenge of identity paradoxes and dilemmas. In this instance, social identity is the metatheoretical perspective which researchers typically apply (Ashforth, 2016a; Ashforth \& Schinoff, 2016; Caza et al., 2018; Cuganesan, 2017; Gioia et al., 2000; Kreiner, Hollensbe, \& Sheep, 2006; Kreiner \& Murphy, 2016; Lee et al., 2015; Miscenko \& Day, 2016; Pratt et al., 2016; Van Tonder, 2004).

The intervention was concerned with a single social identity of the organisational members, namely, their identification with Organisation $\mathrm{ABC}$, their employer. Current OI theory sensitised us in practice to consider the critical importance of bringing about congruence across, and within, personal and social identities for organisational members during an OI intervention.

\section{Using the organisational identity vocabulary}

In the OI space, theoretically and practically, all of the above concepts are highly systemically interdependent, implying each identity concept has to be aligned to, and coherent with, the others, especially in practice: OI, organisational image and corporate identity on the one hand, in and of themselves, and individual identity on the other hand - especially social identity - with all of the aforementioned. Organisational health is a function of the degree of (mis)alignment between these identities (Caza et al., 2018; Hatch \& Schultz, 2002).

During the intervention, we found evidence amongst organisational members of the stress of the unfolding OI work, which we attributed to the cognitive and emotional dissonance arising out the tension between the above as the identity work progressively unfolded in Organisation ABC.

\section{Critically problematising a meta- theoretical framework for the territory called 'Organisational Identity Landscape' \\ Lack of an organisational identity meta- theoretical framework}

With reference to the above discussion about the current OI vocabulary, Haslam et al. (2017) bemoan the detrimental, silo-ing effect of the various stand-alone, meta-theoretical social constructionist, social identity and social actor, meta-theoretical perspectives propagated in OI theory. These perspectives metaphorically inform the different identity concepts (or categories), as discussed above. The aforementioned authors believe these meta-theoretical silos are detrimental to thinking about OI integratively. They therefore propose combining all of these perspectives into a single meta-theoretical framework, which they entitle an 'integrative social interactionist model'.

In a similar vein, Caza et al. (2018) also bemoan the theoretical fragmentation of the current OI literature. They endeavour 
to rather achieve theoretical synthesis and integration by demonstrating the synergetic, complementary relevancies of different meta-theoretical perspectives for different situations encountered in identity work. Essentially, they suggest working with the OI literature eclectically: use what fits the situation.

These are proposals we wholeheartedly endorse at the level of a meta-theoretical perspective in our practice-triggered attempt to arrive at an integrated way of thinking theoretically about OI. This applies even more so in practice. Reality in practice forms a seamless whole that cannot be compartmentalised artificially into separate theoretical realities portending to be representative of a holistic practice. Although necessary, however, we suggest that the above proposed integrations of meta-theoretical perspectives by the aforementioned authors are still insufficient from a practice point of view, as we will argue and demonstrate in what follows in the discussion below.

In our endeavour in practice to interpret the findings of the intervention holistically, organically and systemically, we thus confirmed practically that OI-related literature currently lacks an overarching, integrated meta-theoretical framework (or 'Google map') of the territory called 'Organisational Identity'. At best, we found partial maps of 'regions' within this territory (as confirmed by Caza et al. [2018] and Haslam et al. [2017], as discussed above).

\section{Towards a proposed meta-theoretical framework for organisational identity called 'Organisational Identity Landscape'}

We therefore set out to construct an integrated OI map from the extant literature, in an attempt to understand OI in an integrated, systemic, holistic and organic manner, for both practical and theoretical purposes. The intended map had to be internally coherent, parsimonious yet comprehensive, and needed to create the opportunity for emergent theorising (Eisenhardt et al., 2016). We decided to call our proposed map the 'Organisationl Identity Landscape'.

As an overarching, integrating meta-theoretical framework, the value of our suggested OI landscape is at least threefold: (1) to simplify, organise and integrate - at a meta-level of understanding - the somewhat bewildering complexity and diversity of the field and its literature, especially in its application in practice; (2) to provide a common metalanguage for an all-inclusive, coherent dialogue about OI; and (3) in practice, to assist organisations in framing and structuring their conversations about OI, in this way enabling them to arrive at a unique, customised, systemic framework which can direct and guide their OI thinking, decisions and actions.

Figure 2 depicts our proposed OI landscape as an overarching, integrated meta-theoretical framework of the territory of OI, drawing on the multitude of building blocks (variables or elements) elucidated in the literature (e.g. Ashforth, 2016a; Gioia et al., 2000; Lee et al., 2015; Pratt et al., 2016). As Figure 2 demonstrates, we used a complexity/chaos lens to construct this landscape (see our earlier discussion on the value of adding this 'missing' lens to the literature).

As depicted in Figure 2, our proposed OI landscape is made up of the following:

- The meta-theoretical lenses that organisations can use to view OI (for the sake of completeness, the functionalist lens is also included). Earlier we highlighted the combined, synergistic value of the three lenses (2 to 4) which we used in the intervention and will thus not justify this any further in the subsequent discussion of our findings.

- At the centre of the organisation, the OI/Subunit('s) identity on the one hand and organisational members' identities on the other. These are evident in the ongoing, reciprocal dependency and interaction around OI claims, which manifest in identity work. Within this space, the political interests of organisational members and the leadership of the organisation dynamically affect the crafting and constitution of the organisation's identity (Alvesson et al., 2008; Hatch \& Schultz, 2002; Kenny, Whittle, \& Willmott, 2016). The focus of the intervention was on ensuring a synchronous, co-crafting of the OI and organisational members' identities.

- Organisational components - for example, strategy, culture, and design - which are concrete manifestations of OI in a holographic manner, but which, in a recursive fashion, shape and reinforce OI (Gioia et al., 2013). During the intervention, the focus fell on transforming the organisational culture, in particular Organisation $A B C^{\prime}$ s core values, as expressive of its OI. We define organisational culture as shared ways of seeing, interpreting and doing things in the organisation, based on certain assumptions, beliefs and values (Hatch \& Schultz, 2002; Van Tonder, 2004; Veldsman, 2002).

- The organisational boundary, represented by the dotted-line circle in the figure, separating the organisation from external influences, pressures and trends, to a greater or lesser extent. At stake here, is where boundaries are drawn and their 'thickness' regarding identity.

- The stakeholders, who interact with the organisation and its members regarding its OI, by influencing, imposing, prescribing and even dictating what its identity should and must be. Our intervention in Organisation $\mathrm{ABC}$ formed part of a turnaround strategy which the board initiated, given its dissatisfaction with its projected OI/image, both in the market and amongst its clients.

- The context of space-time in which the organisation, with its members and stakeholders, is embedded. The context allows a certain OI to emerge, which is sustained by, and resonates with, particular contextual qualities (e.g. the 


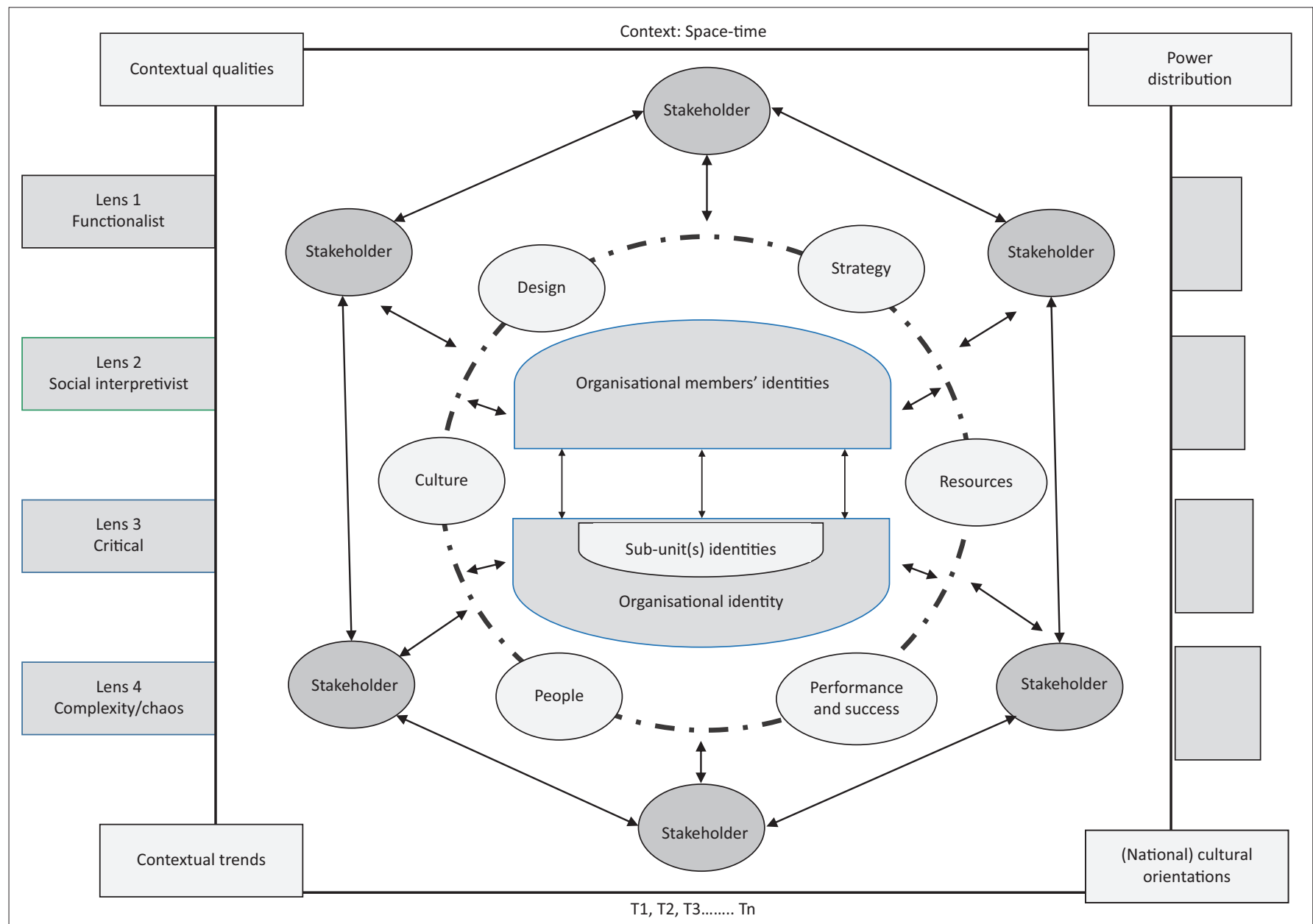

FIGURE 2: Proposed Organisational Identity Landscape as meta-theoretical framework to map the territory called 'Organisational Identity'.

Viccas world); contextual trends such as technological innovation; (national) cultural orientations; power distribution (i.e. those who wield power, and how they deploy it); and how the context with its constituent ingredients (and, hence OI) unfolds over time - T1, T2, T3... Tn - all of which shape that identity. Organisation ABC was originally a South African organisation that globalised over time, and redefined its business as primarily gambling, with hospitality being secondary. The fact that the intervention took place in the South African division of the organisation gave the undertaking a particular local flavour.

- As is typical of a complexity/chaos lens, the two-way arrows connecting the building blocks throughout the OI landscape denote the reciprocal interdependency of, and interaction between, all the building blocks making up the landscape. In this way, we take into account effects and counter-effects, and not linear causality, with the potential of any number of patterns emerging - whether virtuous or vicious - across the landscape.

So what was the value-add of our proposed OI Metatheoretical Framework, called OI landscape, in making sense and giving meaning to the findings arising out of the OI intervention, and in the process integrating and validating the current OI literature?
Demonstrating in practice the value of the Organisational Identity Landscape as a meta-theoretical framework to integrate and validate the current organisational Identity Literature

Given the space constraints of this article, the ensuing discussion drills down into some of the relevant building blocks and relationships which constitute the OI landscape (depicted in Figure 2), with respect to the stated intervention, to demonstrate, firstly, the value of the Landscape in integrating - systemically and holistically - the OI literature; and, secondly, to validate (or call into question) the existing literature through critical problematising; and thirdly and finally, to interpret the findings of the intervention in an integrative manner.

\section{Individual in relation to his or her subunit and organisation}

Up for contention in theOIliterature is whether for organisational members, the primary point of 'one-ness with' and 'belonging to' is their subunit and/or the organisation as a whole, the 'nestedness' of OI (Ashforth, 2016b; Ashforth et al., 2008; 
Humphreys \& Brown, 2002). During the intervention, we found that organisational members related and predominantly deemed themselves as belonging to their organisational subunit, and seemingly, identity formed primarily at a subunit level. The broader, overarching OI was a secondary point of identification. This was further evident in the language organisational members used when referring to the group they identified with and belonged to, being primarily their subunit.

The literature revealed possible different organisational members' identification responses with their organisation: authentic (positive oneness/belonging); neutral (neither oneness nor belonging); ambivalence/schizo-identification (oneness with, and belonging to some parts of organisation, but not others); or disidentification (no oneness/no belonging) (Ashforth, 2016a, 2016b; Hogg \& Terry, 2000; Humphreys \& Brown, 2002).

During the intervention, we confirmed ambivalence/schizoidentification on the part of employees regarding certain aspects of the new OI, but not with regard to the organisation as a whole. As indicated earlier, subunit identification was dominant. This was evident in the desire some subunits expressed in seeking permission to impute certain aspects of identity which were unique to their own subunit, as opposed to merely adopting the broader OI as the only or single identity.

\section{The organisation in relation to its own identity}

A further debating point in the literature is whether an organisation has a uniform OI or multiple identities.

Do different conceptualisations exist as regards what is core, distinctive and enduring about the organisation? In the case of multiple identities, the distinction is between: (1) ideographic multiplicity, that is, different membership groupings in the organisation holding different views regarding its identity; and (2) holographic multiplicity, that is, the same grouping holding different views regarding the organisation's identity (Albert \& Whetten, 1985; Glynn, 2000; Hogg \& Terry, 2000; Humphreys \& Brown, 2002).

In the first instance in particular, it would result in visible identity conflict between different groupings (sub-units) in the organisation. In the second instance, intra-subunit identity tensions would arise. At an organisational member level, competing, multiple identity claims from different sources (e.g. one's own sub-unit and the organisation, as in Organisation $\mathrm{ABC}$ ) would typically result in members hierarchically prioritising the respective claims: members may not identify with all claims equally or identify with all claims at the same time. Members can resolve competing, multiple identity claims by using one of four tactics: compartmentalisation (preserve all of the claims, but keep them apart); deletion (delete or ignore one or more of the claims); integration (fuse claims into a new whole); or aggregation (keep all claims, but seek a common dominator) (Solomon \& Casey, 2017).
During the intervention, we found evidence of compartmentalised, ideographic multiplicity: (1) different subunits viewed the OI of Organisation ABC differently; and (2) membership groups within subunits - depending on their role or area of specialisation - viewed the organisation's identity differently. Team members working in the hospitality division had significantly different perceptions of the identity of Organisation ABC than team members associated with gaming. We observed that the premium business units had a distinctive identity across different geographies, as was the case with more cost-sensitive business units.

Premium brand business units based their identities on an external 'once-in-a-lifetime' client experience. Costsensitive business units, by contrast, built their identities around an image of a 'trusted' and 'always-the-same' client experience. During the intervention, these differences proved significant in the sense that the premium brands identified themes which depicted an external client-focused perspective (e.g. 'client first' experiences). Cost-sensitive units spoke more about an internal perspective (e.g. teams trusting one another). This difference further highlighted the various perspectives existing within these respective brands' identities.

\section{Organisational identity in relation to organisational components}

In our earlier discussion of the OI landscape, we identified recursive relationships between OI and organisational components such as strategy, structure, culture, people, resources, and performance/success. In the literature, it is posited that $\mathrm{OI}$ is located at a deeper, intangible level at the centre of the organisation. Organisational identity is thereafter translated into, and expressive of, organisational components at a more visible, tangible level 'encircling' its identity. Organisational components operationalise, institutionalise and reinforce identity (Gioia et al., 2000; Humphreys \& Brown, 2002; Ravashi, 2016).

Our intervention validated this relationship, as posited in the literature: we could use the more visible core values in the operationalisation and institutionalisation of Organisation $A B C$ 's desired, deeper identity.

We also found that, in the absence of a coherent, overarching narrative, organisational culture - as a concrete expression of OI - can either reinforce, fragment or disintegrate that identity. The compartmentalised, ideographic multiplicity identity contributed to a fragmented OI for Organisation $\mathrm{ABC}$, which we had to counter deliberately throughout the intervention.

\section{Organisational identity in relation to organisational boundaries}

The literature which we consulted revealed that the identity of an organisation is a function of, and determined by, where the organisation decides to draw its boundaries, both 
internally and externally. The degree of influence on OI is a function of how permeable the drawn boundaries are: 'thick' boundaries are strong, relatively impermeable and close the organisation/its sub-units off to outside influences. 'Thin' boundaries are weak, relatively permeable, and open the organisation/its sub-units to outside influences.

Drawing boundaries - physically, cognitively, emotionally and/or behaviourally - enables the organisation to segment itself into multiple identities, along separate organisational domains. Or, it can create an integrated identity for a single domain (Knapp, Smith, Kreiner, Sundaramurthy, \& Barton, 2013; Kreiner \& Murphy, 2016).

Based on our observations during the intervention, we can confirm the criticality of boundaries in the process of forming an OI. We found that Organisation ABC consistently battled to establish its boundaries.

Despite promoting the internal drawing of clear boundaries, the leadership of Organisation ABC allowed external influences to influence the identity-crafting process. This happened when the organisation undertook external market research; welcomed feedback from existing clients; and sought input from industry bodies. Leadership thus drew 'thin' boundaries.

As reported above, different business units within Organisation $\mathrm{ABC}$ drew different boundaries, depending on their offering to the market in terms of defining their subunit identities, as well as their standing in the broader organisational pecking order. As already elucidated, the external boundaries appeared to be thin, allowing strong external influences to permeate. By contrast, in many instances thick internal boundaries existed between subunits, buffering them from internal influences from the senior leadership of Organisation $\mathrm{ABC}$, which allowed them to nurture and protect their sub-unit identity, and do aggressively so. We would argue that the co-existence of thin and thick boundaries, as observed during our intervention, contributed to compartmentalised, ideographic OI multiplicity within Organisation ABC.

\section{Organisation in relation to its context: Stakeholders}

Organisational identities vary to a greater or lesser degree across organisations, resulting from the forcefulness of contextual and stakeholder demands, expectations, and the prescriptions which stakeholders impose on the organisation with respect to its values, beliefs, policies, standards, and practices, given their power over the organisation, its leadership and members.

Stakeholders include the likes of suppliers, customers, shareowners, regulators, professional bodies, the community, competitors, lobby groups, religious groupings and thought leaders. The desired, espoused and experienced organisational identities must have legitimacy and credibility with all stakeholders to allow organisational members to build goodwill and relationships (or social capital) with them (Besharov \& Brickson, 2016; Gioia et al., 2000, 2013; Humphreys \& Brown, 2002; Li, Fan \& Zhao, 2015; Rockwell, 2019; Scott \& Lane, 2000; Sillince \& Golant, 2018).

Through unfolding, iterative interactions, the respective political interests of organisational members and stakeholders drive and shape identity work, as manifested in the dialectical tension between control and autonomy (Kenny et al., 2016; Sillince \& Golant, 2018). This dynamic was aptly illustrated during the intervention - using a critical lens - by the strong pressure (i.e. power) the board of Organisation ABC exerted on its leadership to change the organisation's identity.

Tension for the organisation revolved around how to be the same as others in its industry yet, simultaneously, distinctly different. In other words, finding the organisation's optimal distinctiveness (Brewer, quoted by Gioia et al., 2013; Zuckerman, 2016). The critical lens is invaluable for understanding how power shapes organisation-stakeholder relationships and interactions. During the intervention we noted that the predominant view was to allow external influence on the part of key stakeholders - market competitors, client feedback and industry and regulatory bodies, given the power they wield to define Organisation $A B C$ 's identity, a confirmation of a case of 'thin' boundaries, as discussed earlier.

Nonetheless, we found that, because of an attempt to align the OI more closely to market expectations, organisational members started to disassociate from the new, aspirational identity. The new market positioning portrayed the organisation as 'modern', 'unique' and a 'market leader'. Yet, members' experienced reality was of an organisation that was 'tired', 'a follower', and 'boring'. A real gap thus opened up between the new OI and members' everyday identityrelated experiences in Organisation $A B C$, creating a legitimacy/credibility crisis around identity; OI; and social, individual identity amongst organisational members.

\section{Organisation in relation to its context: Power distribution}

A critical contextual variable of OI is who holds the power internally, and external to the organisation - to make, impose, regulate and legitimise identity-related claims (Alvesson et al., 2008; Alvesson \& Robertson, 2016; Besharov \& Brickson, 2016; Humphreys \& Brown, 2002). Again, the critical lens is most relevant for making sense of this relationship.

Even though the leadership team of Organisation ABC purported to adopt a collaborative, interventionist approach that ostensibly distributed power participatively to all organisational members with respect to the identity work, the members' experienced reality was vastly different. Members were seemingly allowed to participate fully in the identity-crafting process, but this was done within the ambit of leadership 'expecting employees to come up with the right answers', which management had already (pre)defined. 
During the intervention, we found that leaders battled to let go of their own perspectives of what the OI should and must be. Leadership also influenced the identity-crafting process in a way which allowed them to retain control of what the OI should and must be - a clear example of a self-fulfilling prophesy. This under-the-water power struggle undermined the perceived authenticity, transparency and legitimacy of the identity work amongst organisational members.

\section{Organisation in relation to its context: (National) cultural orientations}

(National) cultural orientations (e.g. individualism/ collectivism, time-orientation and uncertainty avoidance) play a role in determining the nature and dynamics of organisational and individual identity - an angle which has not received much attention in the literature (Caza et al., 2018).

In collectivistic, national cultures, the power and effects of OI as a collectively shared feature of the organisation appear to be stronger (Lee et al., 2015). During the intervention, we found a strong coherence between OI and the predominant approach of $u b u n t u$ (i.e. a person is a person through other people) and the collectivist, national cultural orientation present amongst the vast majority of South African employees.

\section{Insights gained from and implications of our journey up to this point in critically problematising existing organisational identity theory against practice}

What insights with implications have we arrived at this point in our journey of critically problematising existing OI theory against practice. In this part of our journey, we have covered the dominant Thinking Framework infusing current OI literature.

\section{At least three insights appear to have emerged:}

- Firstly, to make proper sense of the richness and multidimensionality of OI, both in theory and in practice, it is imperative to make use of multiple meta-theoretical lenses. The pre-dominant functionalist lens, with its unidirectional, linear, causal approach, proved severely wanting and restrictive in terms of understanding the reciprocally interacting, multi-dynamic, multidimensional and organic nature of OI observed in practice. Using an additional three lenses, contributed significantly to a richer and deeper understanding OI: (1) a complexity/chaos lens for holistic insight into OI with its interdependent, reciprocally influencing constituent elements, both conceptually and practically; (2) an interpretivist lens to understand OI as something which individuals and organisations dynamically and continuously co-construct; and (3) a critical lens to provide insight into the impact of power in shaping the OI process and outcomes.

- Secondly, the current OI vocabulary made up of the basic terms Identity; Organisational Identity with the distinguishing features of OI, namely, core, distinctive and enduring; Organisational Image (or reputation); Corporate Identity (or brand) as well as Individual Identity (Personal and Social) appear at present to allow adequately for a basic, comprehensive IO narrative. However though, frequently the concepts are not always defined and used in the same manner in the literature.

- Thirdly, the pressing need for an overarching, integrated meta-theoretical framework (or 'Google map') of the territory called 'Organisational Identity'. The current OI literature is highly, fragmented and silo-ed IO theoretical body of knowledge. At best, partial maps of 'regions' within the OI territory exist. This weakness turns into a real crisis when one wants to make sense of $\mathrm{OI}$ in practice where reality forms a seamless whole that cannot be compartmentalised artificially into separate theoretical realities portending to be representative of a holistic practice. We therefore set out to construct such a map from the extant literature, in an attempt to understand OI in an integrated, systemic, holistic and organic manner, for both practical and theoretical purposes, called the 'Organisationl Identity Landscape'.

\section{Conclusion}

Organisations are embedded in an emerging, radically and fundamentally changing world of work, forcing them to consider deeper issues such as Who are we? and Why do we exist? In this world, OI thus has become critically important as a secure and referent anchor.

The purpose of our article is to review critically in a problematising manner, the extant OI literature's power to provide deep insight into practice as referenced against findings from a longitudinal OI identity intervention in a major global, South African organisation. Our aim is to highlight both the strengths and gaps in the current OI literature from a problematising, practice perspective and to suggest how to enrich and extend the extant OI body of knowledge, both theoretically and practically.

Our article is presented in two parts. Part 1 of our article reported here, set out to critically problematise the Thinking Framework of OI: its meta-theoretical lenses, vocabulary and meta-theoretical framework. Insights gained were threefold: first, the imperative to make use of multiple meta-theoretical lenses - and not only the single functionalist lens - in understanding $\mathrm{OI}$ in its full complexity and richness; second, the current OI vocabulary appear at present to allow adequately for a basic, comprehensive IO narrative; and third, the pressing need for an overarching, integrated meta-theoretical framework (or 'Google map') of the territory called 'Organisational Identity', given the fragmented nature of the current OI literature. 
Part 2 of our article will address OI-in-action: the 'application' side of the current OI Thinking Framework, for example, the here-and-now dynamics of OI; the evolution and change of OI over time; and the outcomes of OI work.

\section{Acknowledgements Competing interests}

The authors have declared that no competing interests exist.

\section{Authors' contributions}

All authors equally contributed to this work.

\section{Funding information}

This research received no specific grant from any funding agency in the public, commercial or not-for-profit sectors.

\section{Data availability statement}

Data sharing is not applicable to this article as new data were not created or analysed in this study.

\section{Disclaimer}

The views and opinions expressed in this article are those of the authors and do not necessarily reflect the official policy or position of any affiliated agency of the authors.

\section{References}

Albert, S., Ashforth, B.E., \& Dutton, J.E. (2000). Organisational identity and identification: Charting new waters and building new bridges. Academy of Management Review, 25(1), 13-17. https://doi.org/10.5465/amr.2000.2791600

Albert, S., \& Whetten, D.A. (1985). Organisational identity. Research in Organisational Behavior, 7, 263-295.

Alvesson, M., Ashcraft, K.L., \& Thomas, R. (2008). Identity matters: Reflections on the construction of identity scholarship in organisation studies. Organisation, 15(1), 5-28. https://doi.org/10.1177/1350508407084426

Alvesson, M., \& Robertson, M. (2016). Organisational identity: A critique. In M.G. Pratt, M. Schultz, B.E. Ashforth, \& D. Ravashi (Eds.), The Oxford handbook of organisational identity (pp. 160-180). Oxford: Oxford University Press.

Alvesson, M., \& Sandberg, J. (2011). Generating research questions through problematization. Academy of Management Review, 36(2), 247-271. https://doi. org/10.5465/amr.2009.0188

Amsteus, M.N. (2014). The validity of divergent grounded theory method International Journal of Qualitative Methods, 13(1), 71-87. https://doi.org/10. $1177 / 160940691401300133$

Ashforth, B.E. (2016a). Distinguished scholar invited essay: Exploring identity and identification in organisations - Time for some course corrections. Journal of Leadership \& Organisational Studies, 23(4), 361-373. https://doi.org/10. $1177 / 1548051816667897$

Ashforth, B.E. (2016b). Organisational, subunit, and individual identities. In M.G. Pratt, M. Schultz, B.E. Ashforth, \& D. Ravashi (Eds.), The Oxford handbook of organisational identity (pp. 79-92). Oxford: Oxford University Press.

Ashforth, B.E., Harrison, S.H., \& Corley, K.G. (2008). Identification in organisations: An examination of four fundamental questions. Journal of Management, 34(3) 325-374. https://doi.org/10.1177/0149206308316059

Ashforth, B.E., \& Schinoff, B.S. (2016). Identity under construction: How individuals come to define themselves in organisations. Annual Review of Organisational Psychology and Organisational Behavior, 3, 111-137. https://doi.org/10.1146/ annurev-orgpsych-041015-062322

Ashforth, B.E., Schinoff, B.S., \& Rogers, K.M. (2016). 'I identify with her', 'I identify with him': Unpacking the dynamics of personal identification in organizations. Academy of Management Review, 41, 28-60. https://doi.org/10.5465/amr.2014.0033

Askegaard, C.L.T.S. (2001). Corporate identity and corporate image revisited - A semiotic perspective. European Journal of Marketing, 35(3/4), 292-315. https:// doi.org/10.1108/03090560110381814

Attride-Stirling, J. (2001). Thematic networks: An analytic tool for qualitative research. Qualitative Research, 1(3), 385-405. https://doi.org/10.1177/146879410100100307
Besharov, M.L., \& Brickson, S.L. (2016). Organisational identity and institutional forces: Towards an integrative framework. In M.G. Pratt, M. Schultz, B.E. Ashforth, $\&$ D. Ravashi (Eds.), The Oxford handbook of organisational identity (pp. 396-413). Oxford: Oxford University Press.

Bhatt, M., Van Riel, C.B.M., \& Baumann, M. (2016). Planned organisational identity change: Insights from practice. In M.G. Pratt, M. Schultz, B.E. Ashforth, \& D. Ravashi (Eds.), The Oxford handbook of organisational identity (pp. 219-238). Ravashi (Eds.), The Oxford han
Oxford: Oxford University Press.

Boulton, J.G., Allen, P/M., \& Bowman, C. (2015). Embarking complexity. Strategic perceptive for an age of turbulence. Oxford: Oxford University Press.

Brown, A.D. (2015). Identities and identity work in organisations. International Journal of Management Review, 17(1), 20-40. https://doi.org/10.1111/ijmr.12035

Caza, B. B, Vough, H., \& Puranik, H. (2018). Identity work in organisations and occupations: Definitions, theories, and pathways forward. Journal of Organisational Behavior, 39(7), 889-910. https://doi.org/10.1002/job.2318

Corley, K.G. (2015). A commentary on 'What grounded theory is...': Engaging a phenomenon from the perspective of those living it. Organisational Research Methods, 18(4), 600-605. https://doi.org/10.1177/1094428115574747

Cuganesan, S. (2017). Identity paradoxes: How senior managers and employees negotiate similarity and distinctiveness tensions over time. Organisation Studies, 38(3/4), 489-511. https://doi.org/10.1177/0170840616655482

Eisenhardt, K.M., Graebner, M.E., \& Sonenshein, S. (2016). Grand challenges and inductive methods: Rigor without rigor mortis. Academy of Management Journal, 59(4), 1113-1123. https://doi.org/10.5465/amj.2016.4004

Fendt, J., \& Sachs, W. (2008). Grounded theory method in management research users' perspectives. Organisational Research Methods, 11(3), 430-455. https:// doi.org/10.1177/1094428106297812

Gibney, R., Zagenczyk, T.J., Fuller, J.B., Hester, K., \& Caner, T. (2011). Exploring organisational obstruction and the expanded model of organisational identification. Journal of Applied Social Psychology, 41(5), 1083-1109. https://doi. org/10.1111/j.1559-1816.2011.00748.x

Gioia, D.A., Patvardhan, S.D., Hamilton, A.L., \& Corley, K.G. (2013). Organisational identity formation and change. The Academy of Management Annals, 7(1), 123-192. https://doi.org/10.5465/19416520.2013.762225

Gioia, D.A., Schultz, M., \& Corley, K.G. (2000). Organisational identity, image, and adaptive instability. Academy of Management Review, 25(1), 63-87. https://doi. org/10.2307/259263

Glynn, M.A. (2000). When cymbals become symbols: Conflict over organizational identity within a symphony orchestra. Organisation Science, 11(3), 285-298.

Haslam, S.A., Cornelissen, J.P., \& Werner, M.D. (2017). Meta-theories and metaphors of organisational identity: Integrating social constructionist, social identity, and social actor perspectives within a social interactionist model. Internationa Journal of Management Reviews, 19(3), 318-336. https://doi.org/10.1111/ ijmr.12150

Hatch, M.J., \& Schultz, M. (2002). The dynamics of organisational identity. Human Relations, 55(8), 89-1018. https://doi.org/10.1177/0018726702055008181

Hogg, M.A., \& Terry, D.J. (2000). The dynamic, diverse, and variable faces of organisational identity. Academy of Management Review, 25(1), 150-154. https:// organisational identity. Academy of $M$ doi.org/10.5465/amr.2000.27711645
dent

Humphreys, M., \& Brown, A.D. (2002). Narratives of organisational identity and identification: A case study of hegemony and resistance. Organisation Studies, 23(3), 421-447. https://doi.org/10.1177/0170840602233005

Kenny, K., Whittle, A., \& Willmott, H. (2016). Organisational identity: The significance of power and politics. In M.G. Pratt, M. Schultz, B.E. Ashforth, \& D. Ravashi (Eds.) The Oxford handbook of organisational identity (pp. 141-159). Oxford: Oxford University Press.

Kiriakidou, O., \& Millward, L.J. (2000). Corporate identity: External reality or internal fit. Corporate Communications: An International Journal, 5(1), 49-58. https://doi. org/10.1108/13563280010317587

Knapp, J.R., Smith, B.R., Kreiner, G.E., Sundaramurthy, C., \&. Barton, S.L. (2013) Managing boundaries through identity work: The role of individual and organisational identity tactics. Family Business Review, 26(4), 333-355. https:// doi.org/10.1177/0894486512474036

Kreiner, G.E., Hollensbe, E.C., \& Sheep, M.L. (2006). Where is the 'me' among the 'we'? Identity work and the search for optimal balance. Academy of Management Journal, 49(5), 1031-1057. https://doi.org/10.5465/amj.2006.22798186

Kreiner, G.E., \& Murphy, C. (2016). OI work. In M.G. Pratt, M. Schultz, B.E. Ashforth, \& D. Ravashi (Eds.), The Oxford handbook of organisational identity (pp. 436-454). Oxford: Oxford University Press.

Lee, E.S., Park, T.Y., \& Koo, B. (2015). Identifying organisational identification as a basis for attitudes and behaviours: A meta-analytic review. Psychological Bulletin, 141(5), 1049-1080. https://doi.org/10.1037/bul0000012

Li, Y., Fan, J., \& Zhao, S. (2015). Organisational identification as a double-edged sword: Dual effects on job satisfaction and life satisfaction. Journal of Personnel Psychology, 14(4), 182-191. https://doi.org/10.1027/1866-5888/a000133

Martínez, P., Pérez, A., \& Del Bosque, I.R. (2014). Exploring the role of CSR in the organizational identity of hospitality companies: A case from the Spanish tourism industry. Journal of Business Ethics, 124(1), 47-66.

Miscenko, D., \& Day, D.V. (2016). Identity and identification at work. Organisational Psychology Review, 6(3), 215-247. https://doi.org/10.1177/2041386615584009

Mujib, H. (2017). Organizational identity: An ambiguous concept in practical terms. Administrative Science, 7(28), 1-30. https://doi.org/10.3390/admsci7030028. 
Murray, A. (2019). A new purpose for the corporation. Fortune, September 2019, pp. $42-48$.

Nowell, L.S., Norris, J.M., White, D.E., \& Moules, N.J. (2017). Thematic analysis: Striving to meet the trustworthiness criteria. International Journal of Qualitative Method, 16(1), 1-13. https://doi.org/10.1177/1609406917733847

O'Reilly, K., Paper, D., \& Marx, S. (2012). Demystifying grounded theory for business research. Organisational Research Methods, 15(2), 247-262. https://doi.org/ $10.1177 / 1094428111434559$

Pioch, E.A., \& Gerhard, U. (2014). Organizational culture as differentiator in international retailing. The Service Industries Journal, 34(8), 729-749.

Pratt, M.G. (2016). Hybrid and multiple organisational identities. In M.G. Pratt, M. Schultz, B.E. Ashforth, \& D. Ravashi (Eds.), The Oxford handbook of organisational identity (pp. 106-120). Oxford: Oxford University Press.

Pratt, M.G., Schultz, M., Ashforth, B.E., \& Ravashi, D. (2016). Introduction: Organisational identity, mapping where we have been, where we are, and where we might go. In M.G. Pratt, M. Schultz, B.E. Ashforth, \& D. Ravashi (Eds.), The we might go. In M.G. Pratt, M. Schultz, B.E. Ashforth, \& D. Ravashi (Eds.), The
Oxford handbook of organisational identity (pp. 1-18). Oxford: Oxford University Oxford
Press.

Ravashi, D. (2016). Organisational identity, culture, and image. In M.G. Pratt, M. Schultz, B.E. Ashforth, \& D. Ravashi (Eds.), The Oxford handbook of organisational identity (pp. 65-78). Oxford: Oxford University Press.

Rockwell, S. (2019). A resource-based framework for strategically managing identity. Journal of Organisational Change Management, 32(1), 80-102. https://doi. org/10.1108/JOCM-01-2018-0012

Scott, S.G., \& Lane, V.R. (2000). Fluid, fractured and distinctive? In search of a definition of organisational identity. Academy of Management Review, 25(1), 143-144.

Sillince, J.A.A., \& Golant, B.D. (2018). Making connections: A process model of organisational identification. Human Relations, 71(3), 349-374. https://doi.org/ 10.5465/amr.2000.27711619

Solomon, J., \& Casey, A. (2017). A hierarchical model of organisational identification. Journal of Organisational Psychology, 17(3), 93-111.
The British Academy. (2019). Principles for purposeful business. How to deliver the framework for the future of the corporation. An agenda for business in the 2020s and beyond. London: The British Academy.

Van Rekom, J. (1997). Deriving an operational measure of corporate identity. European Journal of Marketing, 31(5/6), 110-122. https://doi.org/10.1108/eb060640

Van Riel, C.B.M., \& Balmer, J.M.T. (1997). Corporate identity: The concept, its measurement, and management. European Journal of Marketing, 31(5/6), 340355. https://doi.org/10.1108/eb060640

Van Tonder, C.L. (2004). Below-the-surface and powerful: The emerging notion of organisation identity. Organisation Development Journal, 22(2), 68-78.

Veldsman, T.H. (2002). Knitting the organisation together: The warp and weft of organisational culture. In T.H. Veldsman (Ed.), Into the people effectiveness arena: Navigating between chaos and order (pp. 214-239). Johannesburg: Knowledge Resources.

Veldsman, T.H. (2016a). The world of tomorrow: Leadership challenges, demands and requirements. In T.H. Veldsman \& A.J. Johnson (Eds.), Leadership: Perspectives from the front line (pp. 169-188). Johannesburg: KR Publishing.

Veldsman, T.H. (2016b). Leadership engagement with the context. In T.H. Veldsman \& A.J. Johnson (Eds.), Leadership: Perspectives from the front line (pp. 325-340). Johannesburg: KR Publishing.

Walsh, I., Holton, J. A., Bailyn, L., Fernandez, W., Levina, N., \& Glaser, B. (2015). What grounded theory is: A critically reflective conversation among scholars. Organisational Research Methods, 18(4), 581-599. https://doi.org/10.1177/1094428114565028
Restion

Webster, L., \& Mertova, P. (2007). Using narrative inquiry as a research method: An introduction to using critical event narrative analysis in research on learning and teaching. Oxford: Routledge.

Zuckerman, E. (2016). Optimal distinctiveness revisited: An integrative framework for understanding the balance between differentiation and conformity in individual and organisational identities. In M.G. Pratt, M. Schultz, B.E. Ashforth, \& D. Ravashi (Eds.), The Oxford handbook of organisational identity (pp. 183-197). Oxford: Oxford University Press. 